\title{
Erratum to: comparison between inflammation-related markers in peri-implant crevicular fluid and clinical parameters during osseointegration in edentulous jaws
}

\author{
Amália M. Bielemann ${ }^{1} \cdot$ Raissa M. Marcello-Machado ${ }^{2}$. Fábio Renato Manzolli Leite ${ }^{3}$. \\ Frederico Canato Martinho ${ }^{4}$ - Otacílio Luiz Chagas-Júnior ${ }^{5}$ - Altair Antoninha Del Bel Cury ${ }^{6}$. \\ Fernanda Faot ${ }^{7}$
}

Published online: 4 September 2017

(C) Springer-Verlag GmbH Germany 2017

\section{Erratum to: Clinical Oral Investigations}

https://doi.org/10.1007/s00784-017-2169-0

In the online version of the article, the results of the cytokine analyses (page 5 and Table 3 ) should be referred to as "median" instead of "means". In addition, the significant differences between the categorized groups in the Figs. 1-4 were indicated by asterisks, but these asterisks disappeared during the conversion of the figures' source files.

The original article has been corrected.

The online version of the original article can be found at https://doi.org/ 10.1007/s00784-017-2169-0

Fernanda Faot

fernanda.faot@gmail.com

1 School of Dentistry, Federal University of Pelotas, Pelotas, RS, Brazil

2 Piracicaba Dental School, University of Campinas, Piracicaba, SP, Brazil

3 Department of Dentistry and Oral Surgery, Aarhus University, Aarhus, Denmark

4 Department of Restorative Dentistry, Endodontics Division, School of Dentistry, State University of São Paulo, São José dos Campos, SP, Brazil

5 Department of Oral and Maxillofacial Surgery and Maxillofacial Prosthodontics, School of Dentistry, Federal University of Pelotas, Pelotas, RS, Brazil

6 Department of Prosthodontics and Periodontology, School of Dentistry, Piracicaba Dental School, University of Campinas, Piracicaba, Brazil

7 Department of Restorative Dentistry, School of Dentistry, Federal University of Pelotas, Gonçalves Chaves Street 457,

Pelotas, RS 96015-560, Brazil 


\section{Cytokine release according to smoking habit}
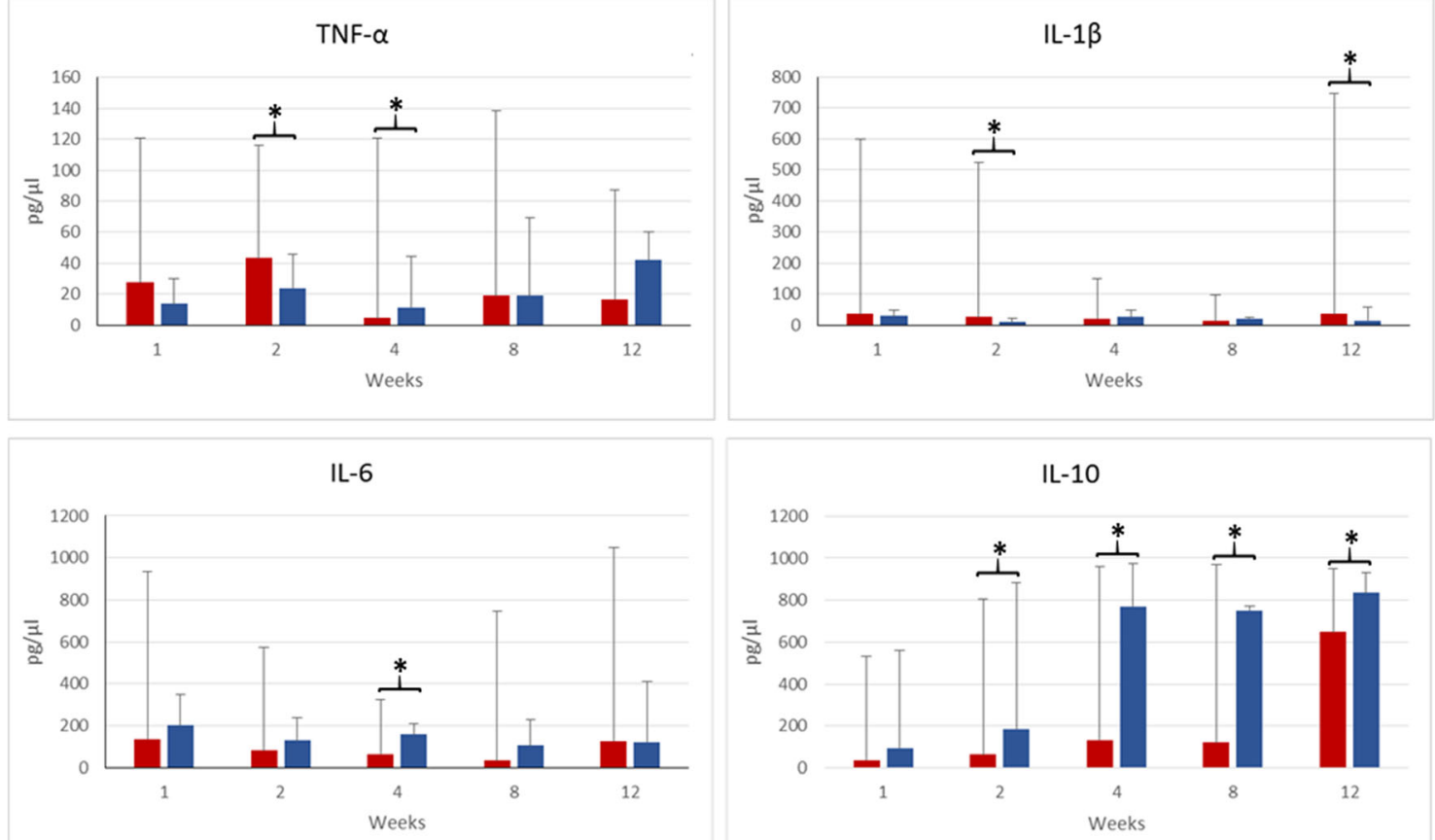

Smoker

Non-Smoker

Fig. 1 Smoking habit versus levels of TNF- $\alpha$, IL-1 $\beta$, IL-6, and IL-10 in the peri-implant fluid (pg/ $\mu$ l) during the evaluation periods

\section{Cytokine release according to bone atrophy}
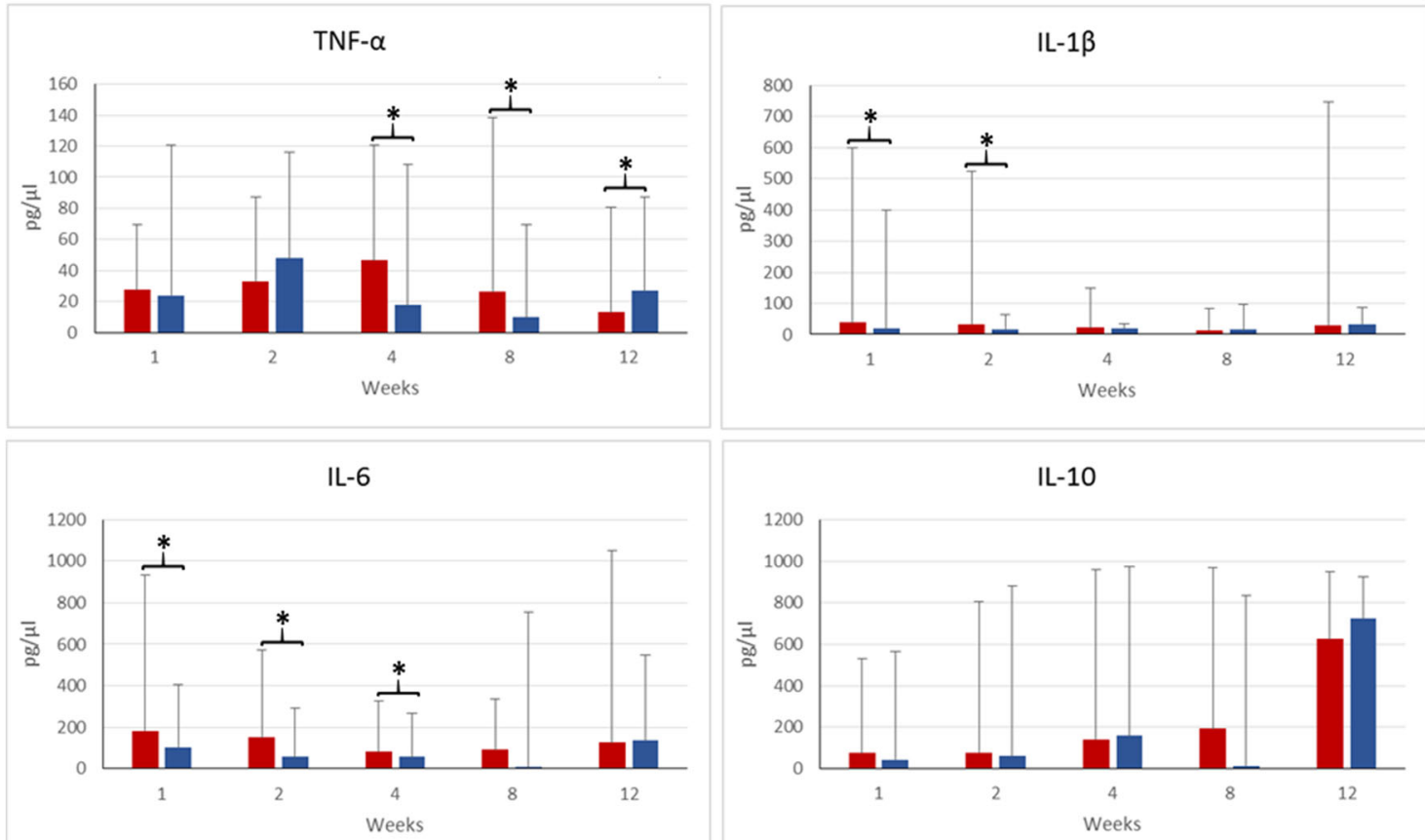

Atrophic

Non-Atrophic

Fig. 2 Bone atrophy versus levels of TNF- $\alpha$, IL-1 $\beta$, IL-6, and IL-10 in the peri-implant fluid (pg/ $\mu$ l) during the evaluation periods 


\section{Cytokine release according to bone type}
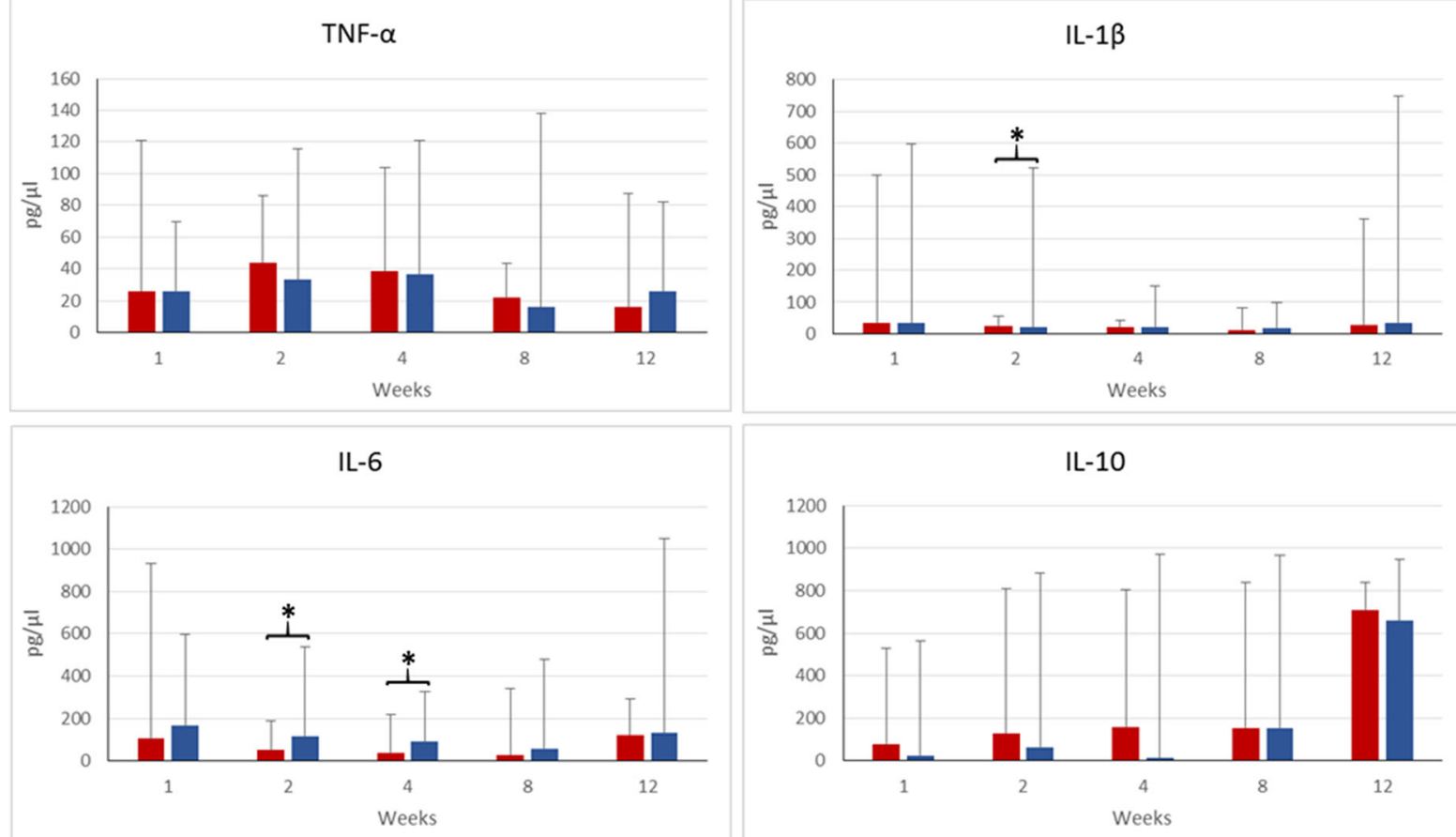

Type I

Type II

Fig. 3 Bone type versus levels of TNF- $\alpha$, IL-1 $\beta$, IL-6, and IL-10 in the peri-implant fluid (pg/ $\mu$ l) during the evaluation periods

\section{Cytokine release according to insertion torque}
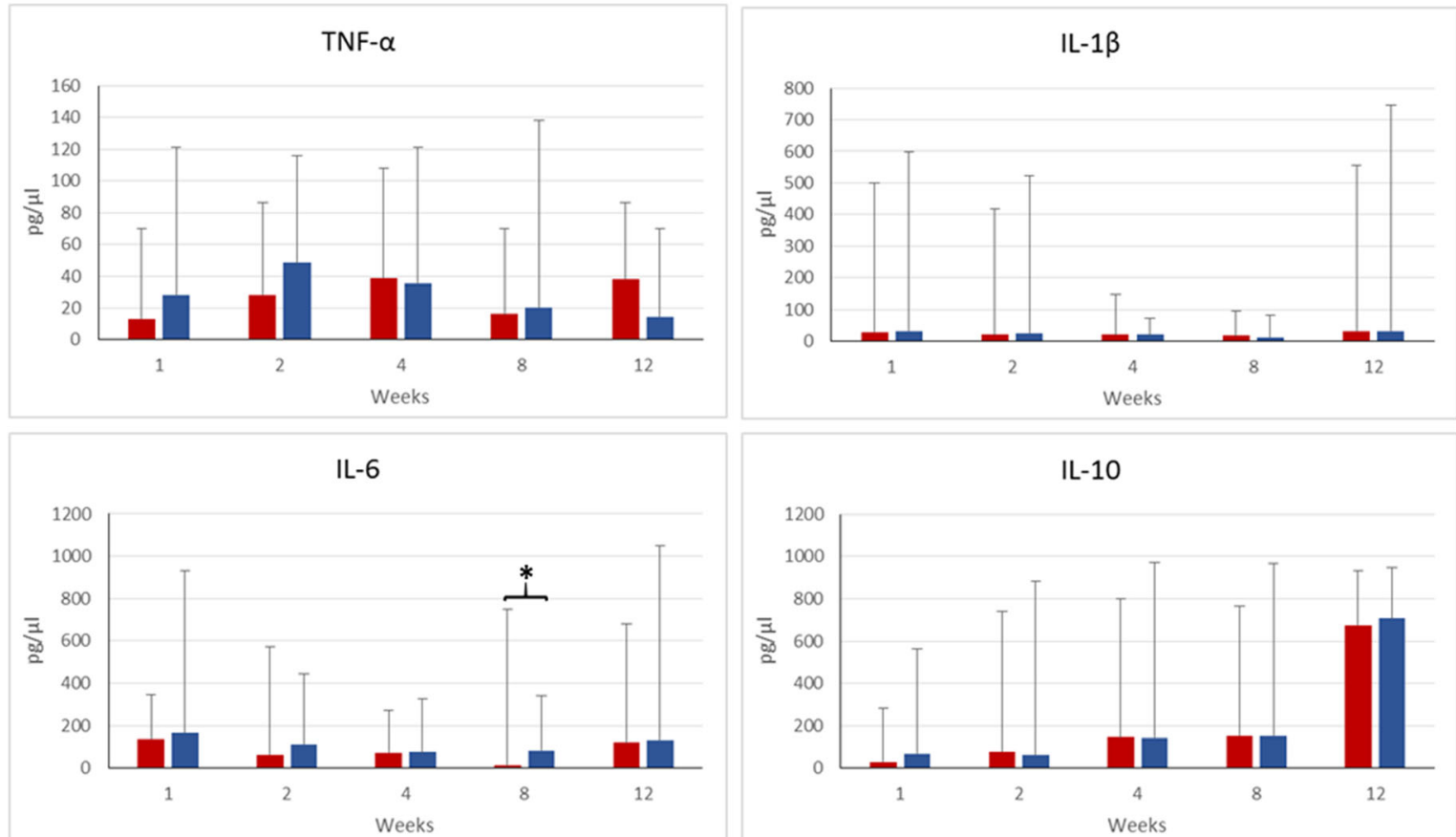

$<32 \mathrm{Ncm}$

$>32 \mathrm{Ncm}$

Fig. 4 Insertion torque versus levels of TNF- $\alpha$, IL-1 $\beta$, IL-6, and IL-10 in the peri-implant fluid (pg/ $\mu$ l) during the evaluation periods 